\title{
Взаимодействие компонентов интеллектуального капитала в процессе создания стоимости фирмы ${ }^{24}$
}

\author{
Найденова Ю.Н. ${ }^{25}$, Осколкова М.А. ${ }^{26}$
}

На сегодняшний день широкое распространение получила теория экономики знаний, в соответствии с которой наиважнейшим ресурсом фирм и других экономических агентов являются знания и инструменты управления ими, то есть то, что в литературе определяется термином «ИК». С другой стороны, главная цель деятельности фирмы, согласно конщепции управления на основе стоимости (VBM), - это увеличение ее стоимости для всех заинтересованньх сторон. Поэтому для эффективного управления компанией важно понимать, как именно ИК способствует этой цели. Данная работа посвящена исследованию взаимодействия компонентов ИК в прочессе создания стоимости. На основе выборки панельных данных по 64 компаниям Великобритании за 2005-2009 годы выявлено, что существует синергетический эффект от одновременного использования разных компонентов ИК, кроме того, структура ИК может повлиять на создаваемую компанией добавленную стоимость.

\section{JEL: $G 30$}

Ключевые слова: интеллектуальный капитал, создание стоимости, добавленная стоимость, структура активов, отдача от интеллектуального капитала

В конце XX века развитые финансовые рынки США повлияли на смещение акцентов в мировом финансовом менеджменте, сделали приоритетным прирост рыночной стоимости компании, а не показателей ее бухгалтерской отчетности, и привели к зарождению концепции управления на основе стоимости (value-based management, VBM). Эта концепция рассматривает стоимость компании как основную цель ее деятельности, создаваемую в результате использования вложенных инвесторами ресурсов. Однако в эпоху глобализации и «новой экономики» роль материальных активов при создании стоимости отступает на второй план, поскольку они не способны генерировать конкурентные преимущества, при этом возрастает интерес к неосязаемым активам. Неосязаемые активы, или так называемый ИК, включают ценные для компании активы, такие как знания работников, внедренные информационные технологии, приверженность бренду покупателей и налаженные связи с поставщиками. В академической среде неоднократно исследовался вопрос о способности ИК создавать различные виды добавленной стоимости компании и показателях, способных их измерить (Riahi-Belcaoui, 2003; Youndt, 2004; Zeghal, Maaloul, 2010; Pulic, 2000; Stewart, 2002; Байбурина, 2007; Пунтилло, 2009; Kimura at al, 2010; Березинец и др., 2010; Molodchik at al., 2012; Shakina et al, 2012). Несмотря на это, изучение процесса превращения ИК и его компонентов в финансовые результаты деятельности компании до сих пор остается проблемной областью исследований.

Одним из вопросов в данной тематике является вопрос о величине отдачи от неосязаемых активов, выражаемой, в частности, добавленной стоимостью, и необходимости ее измерения. Поскольку ранее расходы инвестиционного типа, такие как расходы на НИОКР, маркетинговые расходы и стоимость тренингов персонала трактовались как издержки организации, а не инвестиции, не возникало потребности в измерении отдачи от

\footnotetext{
${ }^{24}$ В работе использованы результаты, полученные в ходе проекта «Измерение интеллектуального капитала компании», выполненного в рамках Программы «Научный фонд ГУ-ВШЭ» в 2011-2012 годах.

${ }^{25}$ Младший научный сотрудник лаборатории инвестиционного анализа НИУ ВШЭ - Пермь.

${ }^{26}$ Преподаватель кафедры финансового менеджмента НИУ ВШЭ - Пермь.
} 
них. В условиях «новой экономики» и интенсивного использования ИК для управления стоимостью компании необходимо не только рационально вкладывать средства в материальные активы, но также определять, являются ли инвестиции в ИК компании эффективными. Также исследователями поднимается вопрос о форме отдачи от ИК, причем под этим термином подразумевается один из ресурсов, используемых компанией в производстве и, таким образом, являющихся частью ее производственной функции.

\section{1. Форма отдачи от ИК и его компонентов}

Авторы ранних работ (Arthur, 1996; Bontis, 2001; Daum, 2001) утверждают, что интеллектуальные ресурсы, в отличие от материальных, таких как земля, труд и капитал, характеризуются возрастающей отдачей. Основным аргументом в пользу такого свойства исследователи называют то, что благодаря невещественности ИК управление его компонентами обладает эффектом ненулевой суммы, когда вложения многократно окупаются. Даум объясняет это экономией от масштаба за счет того, что при увеличении масштаба деятельности дополнительных вложений в ИК (например, в программное обеспечение или маркетинг) не требуется, либо необходимо лишь тиражирование носителя кодифицированных знаний, затраты на которое несущественны. Следовательно, с некоторой точки перегиба инвестиции в ИК начинают приносить растущую отдачу (Daum, 2001).

C другой точки зрения, может происходить обратный процесс, когда чрезмерное инвестирование в ИК разрушает стоимость. Это можно рассмотреть на примере анализа эффективности расходов инвестиционного типа в рамках концепции экономической добавленной стоимости. В методологии расчета показателя EVA Стерн и Стюарт предлагают капитализировать расходы на НИОКР, маркетинг, рекламу и обучение персонала для того, чтобы отразить их долгосрочное влияние на стоимость компании (Stern, 2003). Таким образом, если рассматривать капитализированную величину как стоимость разработанного благодаря научно-исследовательской деятельности актива, стоимость инвестированного капитала повышается и его рентабельность снижается. В таком случае излишнее инвестирование в интеллектуальные активы, не приводящее к соответствующему повышению операционной прибыли, снижает стоимость компании.

Эмпирические исследования также не находят подтверждения возрастающей отдачи от ИК. Канибано провел анализ существующих на тот момент исследований и выявил, что маркетинговые расходы не имеют четкой взаимосвязи со стоимостью компании (Canibano, 2000). Хуанг и Вонг (Huang, Wang, 2008) с помощью регрессионного анализа проверили силу линейной взаимосвязи рыночной стоимости собственного капитала и прокси-показателей ИК и выявили, что эти виды инвестиций не всегда положительно взаимосвязаны с капитализацией. В качестве таких показателей были использованы маркетинговые издержки в расчете на одну акцию, соотношение расходов на НИОКР и чистого операционного дохода, административные издержки на одного работника. Более того, в компаниях традиционных (индустриальных) отраслей расходы на накопление ИК организации положительно или нейтрально связаны с капитализацией, a в высокотехнологичной электронной промышленности расходы на маркетинг имеют устойчивую отрицательную взаимосвязь со стоимостью компании. Это может свидетельствовать о том, что в традиционных отраслях инвестирование в неосязаемые интеллектуальные активы носит умеренный характер и не достигает точки насыщения, поэтому не создает значительных преимуществ, но и не приводит к разрушению стоимости. Вероятно, в отличие от традиционных, в отраслях, где ИК используется более интенсивно, инвестиции в него могут превысить необходимое количество, что приведет к неэффективности и разрушению стоимости.

Ряд исследований (Shiu, 2006; Chen, Cheng, Hwang, 2005; Diez et al. 2010; Гаранина, 2009 и др.), посвященных определению вклада ИК в стоимость компании, также показывает схожие результаты. Обнаруживается, что для некоторых компаний характерна отрицательная отдача от интеллектуальных активов. В своем исследовании Гаранина 
предложила метод оценки нематериальных активов при помощи модели остаточной операционной прибыли REOI (Residual Operating Income) для определения фундаментальной стоимости собственного капитала (Гаранина, 2009). В данном случае под нематериальными активами подразумевается не перечень нематериальных активов бухгалтерского баланса, а весь объем неосязаемых активов, которым владеет компания. В общем виде данная модель представляет собой капитализированную величину остаточной прибыли, рассчитанной на основе чистых активов организации и спреда между фактической доходностью компании и среднеотраслевой.

В этом случае эффекты влияния нематериальных активов на общую доходность могут быть как положительными - в случае превышения доходности компании над среднеотраслевым уровнем, так и отрицательными - в противном случае. Таким образом, фундаментальная стоимость нематериальных активов может быть даже при неотрицательном значении доходности как положительной, так и отрицательной. Результаты эмпирических исследований показали, что фундаментальная стоимость неосязаемых активов, определенная по модели Гараниной, с течением времени не только не растет, но даже падает и становится отрицательной (рис. 1).

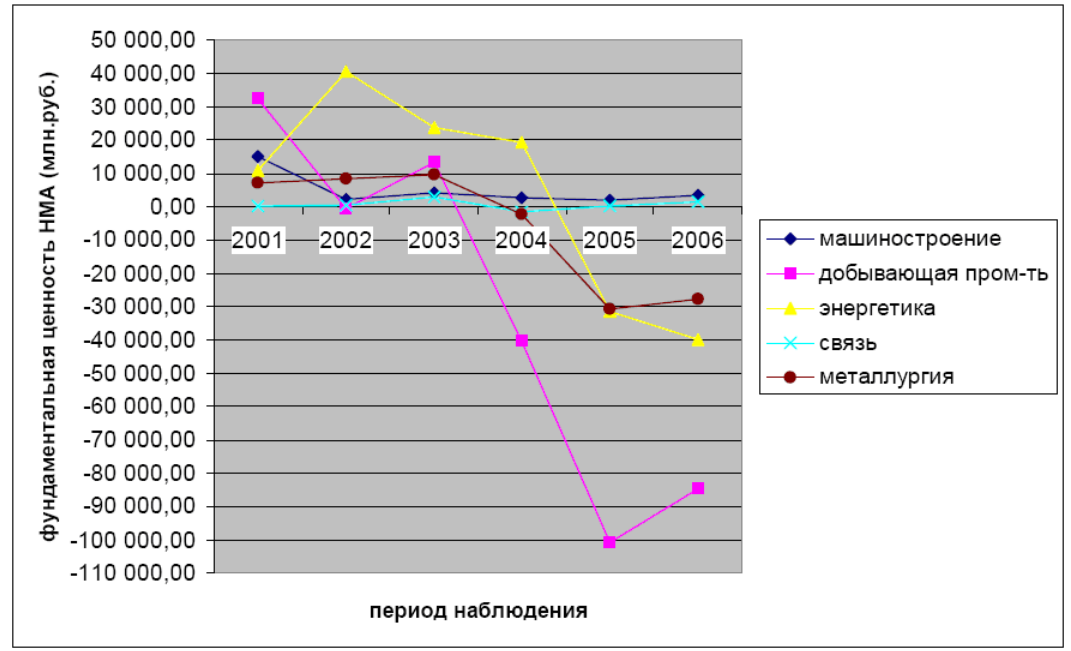

Рисунок 1. Фундаментальная стоимость нематериальных активов

Источник: (Гаранина, 2009).

Возможно, данный парадокс может быть объяснен тем, что компании имеют неоптимальную комбинацию активов и причиной отрицательного воздействия на стоимость капитала является несбалансированность между количеством материальных и неосязаемых активов компании и/или дисбаланса между компонентами интеллектуального капитала.

Если считать интеллектуальный капитал частью портфеля активов компании, то, вероятно, существует оптимальная структура активов, позволяющая создавать наибольшую стоимость. Как предполагают некоторые исследователи, стоимость интеллектуального капитала подчиняется правилу мультипликации, то есть существует некая синергия между его компонентами. Предполагая некую комплементарность интеллектуальных активов, можно предположить, что недоинвестирование в один из компонентов также ведет к значительному недоиспользованию потенциала роста стоимости компании. И наоборот, излишек инвестирования приведет к высоким затратам при отсутствии роста отдачи. Таким образом, возможно существование предела насыщения компонентами интеллектуального капитала, превышение которого ведет к разрушению стоимости компании.

Хуанг и Лью (Huang, Liu, 2005) выявили, что взаимосвязь инновационного капитала, в частности НИОКР, с эффективностью работы компании является нелинейной и предположительно U-образной. Если это действительно так, то отдача от интеллектуального капитала, по крайней мере от некоторых его компонентов, может подчиняться закону возрастающей отдачи до некоторой точки перегиба, а затем - закону убывающей отдачи. Следовательно, возможна ситуация, когда инвестирование в интеллектуальные активы даст 
отрицательную отдачу, станет неэффективным и не приведет к росту стоимости компании.

Таким образом, обзор существующих исследований демонстрирует, что вопрос о форме отдачи от ИК и значимости структуры активов, в том числе неосязаемых, с точки зрения создания стоимости остается дискуссионным, поскольку теоретические предположения расходятся с результатами эмпирических исследований. На основе этого мы выдвинули две гипотезы, которые необходимо проверить:

1. Существует синергетический эффект от одновременного использования разных компонентов интеллектуального капитала. Другими словами, для ИК работает правило мультипликативности, которое подразумевает, что стоимость компании зависит не от суммы стоимостей компонентов ИК, а от их произведения.

2. Структура материальных и интеллектуальных активов влияет на стоимость компании. По аналогии с микроэкономическим представлением об оптимальном соотношении труда и капитала в компании, можно сделать предположение о наличии оптимального соотношения между материальными и интеллектуальными активами. Кроме того, структура самого ИК влияет на создание добавленной стоимости.

\section{2. Выбор показателей создания добавленной стоимости}

За последние несколько десятилетий было создано множество теорий и концепций, делающих попытки измерения стоимости нематериальных активов или ИК и его элементов. Наиболее полный обзор методов измерения представлен на сайте Карла-Эрика Свейби. Но, несмотря на существование целого ряда методов, пытающихся измерить стоимость ИК, которым владеет организация, определить его степень влияния на финансовые результаты деятельности компании, либо отделить созданную неосязаемыми активами стоимость от стоимости, генерируемой материальными активами, на сегодняшний день не существует общепризнанного метода, позволяющего решить эти проблемы. Наиболее известными методами, предложенными для идентификации процесса превращения ИК и его компонентов в финансовые результаты деятельности компании, используемыми в рамках настоящего исследования, являются концепции Q Тобина (Tobin, 1969), EVA (Stern, 2003), VAIC (Pulic, 1997), FGV (Руус и др., 2008), MVA.

Основной предпосылкой рассмотрения EVA (еconomic value added, экономическая добавленная стоимость) как косвенного показателя ИК является предположение о том, что нормальная экономическая прибыль создается физическими и финансовыми активами, тогда как сверхприбыль - нефинансовыми (Lev, 1999).

Показатель FGV (future growth value, стоимость будущего роста) был разработан создателями концепции EVA компанией SternStewart\&Co, как ее развитие. В ряде работ он рассматривается как прокси-показатель ИК, который отражает мнение рынка о потенциале будущего роста компании и достигает наивысшего значения в отраслях, характеризующихся активным использованием инновационных продуктов (Руус и др., 2008).

В отличие от показателя EVA, показатель VAIC, предложенный Пуликом, направлен на измерение добавленной стоимости, созданной компонентами ИК, а именно - структурным и человеческим, а также инвестированным капиталом. Ввиду того что для оценки показателя достаточно использовать только общедоступную финансовую информацию, а также несложной методологии, показатель активно используется в исследованиях.

Для объяснения существующего спреда между капитализацией и балансовой стоимостью активов было предложено множество вариантов, при этом одним из наиболее популярных и часто исследуемых на сегодняшний день является влияние ИК и его компонентов на стоимость компании (Lev, Zarowin, 1999). Разница между балансовой и рыночной стоимостью компании может быть использована как прокси-показатель ИК, а также в качестве показателя, идентифицирующего важность его использования, однако не является показателем стоимости самого ИК компании (Rodov, Leliaert, 2002).

Соотношение между рыночной стоимостью и стоимостью замещения активов 
компании, называемое коэффициентом Q Тобина, было разработано в 1969 году американским экономистом Джеймсом Тобином для предсказания целесообразности капиталовложений. Вследствие многочисленной критики коэффициент не используется по своему прямому назначению как показатель бухгалтерской стоимости компании и настроения инвесторов, однако в рамках ряда современных исследований, посвященных усилению роли неосязаемых активов в новой экономике, Q Тобина рассматривается как прокси-показатель ИК. Также во многих работах используется близкий показатель соотношения рыночной и балансовой стоимости активов $\mathrm{P} / \mathrm{BV}$, поскольку определить стоимость замещения активов компании трудоемко.

\section{3. Выбор прокси-показателей интеллектуального капитала}

Поскольку в научной литературе до сих пор нет единого мнения относительно общепринятой структуры ИК, его наличие и величина могут быть измерены только с помощью аппроксимирующих показателей. В работе была использована трехкомпонентная структура ИК (с выделением таких видов капитала, как структурный, человеческий и финансовый) и показатели, представленные в таблице 1. Выбор показателей проводился на основании обзора эмпирических исследований, посвященных ИК и создаваемой им стоимости (Zickgraf, Mertonetal, 2007; Starowiz, Marretal, 2005; Mouritsen, Bukh, 2003).

Таблица 1

Прокси-показатели интеллектуальных ресурсов

\begin{tabular}{|c|c|c|c|}
\hline & $\begin{array}{l}\text { Структурный капитал } \\
\text { SC }\end{array}$ & $\begin{array}{l}\text { Человеческий } \\
\text { капитал НС }\end{array}$ & $\begin{array}{l}\text { Отношенческий } \\
\text { капитал }\end{array}$ \\
\hline Финансовые & $\begin{array}{l}\text { - Нематериальные } \\
\text { активы } \\
\text { - Расходы на НИОКР }\end{array}$ & - Заработная плата & $\begin{array}{l}\text { - Доля коммерческих } \\
\text { расходов }\end{array}$ \\
\hline Нефинансовые & $\begin{array}{ll}\text { - Количество } & \text { патентов, } \\
\text { лицензий, } & \text { торговых } \\
\text { марок } & \\
\text { - Наличие ERP систем }\end{array}$ & $\begin{array}{l}\text { - Количество } \\
\text { работников } \\
\text { - Квалификация } \\
\text { членов совета } \\
\text { директоров } \\
\text { - Доля } \\
\text { собственников } \\
\text { числе директоров }\end{array}$ & $\begin{array}{l}\text { - Известность бренда } \\
\text { - Цитируемость сайта } \\
\text { компании } \\
\text { - Нахождение офиса в } \\
\text { столице } \\
\text { - Нахождение офиса в } \\
\text { городе-миллионнике } \\
\text { - Наличие дочерних } \\
\text { компаний } \\
\text { - Качество сайта }\end{array}$ \\
\hline
\end{tabular}

Кратко опишем выбранные прокси-показатели. Часть из них определялась на основе отчетности компании, преобразованной в Global Format в базе данных Amadeus (Bureau Van Dijk):

1. Нематериальные активы.

2. Расходы на НИОКР за текущий год.

3. Заработная плата.

4. Доля коммерческих расходов. Показатель определялся как отношение величины коммерческих расходов к общей сумме расходов.

Также были собраны следующие нефинансовые показатели:

5. Количество патентов, лицензий и торговых марок, имеющихся в распоряжении у компании. Показатель рассчитывался на основании данных компании и международной патентной базы QPAT.

6. Наличие систем управления предприятием (Enterprise Resource Planning, ERP). Бинарная переменная, характеризующая наличие (1) или отсутствие (0) интегрированных 
систем управления компанией, основанных на информационных технологиях, используемых для управления ее ресурсами (ERP, Oracle, NAVISION, NAV, SQL, SAP и др.).

7. Количество работников. Использовалось общее количество сотрудников компании на конец года.

8. Квалификация членов совета директоров. Совет считался квалифицированным, если более трети директоров имели степень $\mathrm{PhD}$ и/или долгий срок работы. Качественная переменная, принимающая значения от 0 до 2.

9. Доля собственников в числе директоров. Определялось отношение числа директоров компании, владеющих ее акциями, к общему числу совета.

10. Известность бренда. Бренд компании считался известным, если она входила в международный рейтинг Global 1000, отбор в который производится на основании финансовых, экологических, социальных факторов. Показатель представляет собой бинарную величину.

11. Цитируемость сайта компании. Данный показатель определялся на основании критерия компании Google (Googlerank), учитывающего количество запросов, прямых и перекрестных ссылок, и имел значение от 0 до 10.

12. Нахождение офиса в столице. Показатель определяется как бинарная величина и характеризует отношенческого капитала компании, поскольку столица страны, (территориального округа, области и т.д.) отличается высокой степенью концентрации компаний-партнеров, поставщиков и клиентов.

13. Нахождение офиса в городе-миллионнике. Аналогично предыдущему показателю, предполагается наличие большей степени развития отношенческого капитала при наличии большего количества потенциальных стейкхолдеров. Показатель определяется как бинарная величина.

14. Количество дочерних компаний.

15. Качество сайта. Предполагается, что компания с высоким уровнем отношенческого капитала имеет более полный и удобный для пользователя сайт. При расчете показателя использовались четыре критерия: наличие специального раздела для инвесторов компании; наличие вариантов выбора языка; использование анимированных изображений; количеством страниц сайта. Удовлетворение каждого критерия характеризуется как 1 балл и 0 в обратном случае. Итоговый параметр «качество сайта» определяется как сумма баллов по всем критериям и таким образом находится в пределах от 0 до 4.

\section{4. Создание выборки}

Для тестирования выдвинутых гипотез была создана выборка, созданная в два этапа. В первую очередь отобраны компании, удовлетворяющие следующим требованиям:

1. Акции компании торгуются на фондовой бирже, поскольку в работе планируется использование рыночной оценки собственного капитала компаний.

2. Финансовые, операционные и прочие показатели отчетности доступны за период 2005-2009 годов.

3. Компания осуществляет деятельность на территории Великобритании. Выбор страны обусловлен тем, что британский финансовый рынок является развитым, на нем активно торгуются многие компании. Кроме того, в соответствии с KI-индексом (Knowledge index), который отражает способность страны создавать, усваивать и распространять знания, Великобритания может быть отнесена к первому квантилю рейтинга (9-е место из 145 возможных). Высокое место в рейтинге позволяет предположить высокую вероятность того, что исследование позволит достаточно четко идентифицировать процесс трансформации ИК, выражаемого выбранными аппроксимирующими показателями, в стоимость компании.

4. Компания принадлежит одной из следующих отраслей: оптовая и розничная торговля, производство машин и оборудования, химическая промышленность (включая нефтехимию), транспорт и связь. Данные отрасли характеризуются значительным числом 
компаний в среднем по отобранным странам, что позволяет собрать достаточное количество необходимых данных для анализа выборки в отраслевом разрезе.

5. Количество сотрудников компании находится в диапазоне от 500 до 20000 человек. Данная характеристика обеспечивает исключение наиболее малых и наиболее крупных фирм, для которых возможна своя специфика деятельности.

Выборка, собранная с учетом указанных требований, включает 172 компании, осуществляющих деятельность на территории Великобритании.

Второй этап заключается в отборе компаний, по которым могут быть определены выбранные прокси-показатели деятельности компаний, отражающие уровень использования и инвестирования в ИК, а также рассчитаны показатели стоимости, им созданной. Также акции компаний должны активно торговаться на фондовой бирже в течение всего рассматриваемого периода, поскольку данное условие является необходимым для того, чтобы рыночная капитализация компании адекватно отражала фундаментальную стоимость ее акций.

В результате отбора по этим критериям была получена выборка, состоящая из 64 компаний Великобритании. Следует отметить, что наиболее проблематичной областью в публикуемой отчетности стало предоставление информации о числе сотрудников и величине вложений в научно-исследовательские разработки.

Таблица 2

Описательная статистика показателей стоимости, созданной интеллектуальным капиталом

\begin{tabular}{|l|r|r|r|r|r|r|}
\hline & \multicolumn{1}{|c|}{ EVA } & \multicolumn{1}{c|}{ FGV } & \multicolumn{1}{c|}{ MVA } & \multicolumn{1}{c|}{ VAIC } & \multicolumn{1}{c|}{ P/BV } & \multicolumn{1}{c|}{$\begin{array}{c}\text { Инвестированный } \\
\text { капитал }\end{array}$} \\
\hline $\begin{array}{l}\text { Среднее } \\
\text { значение }\end{array}$ & 3913,8 & 732638,0 & $-77839,6$ & 5,7 & 1,1 & 456347,4 \\
\hline Медиана & 4636,2 & 424426,2 & $-24510,3$ & 5,1 & 0,9 & 239043,4 \\
\hline $\begin{array}{l}\text { Максимальное } \\
\text { значение }\end{array}$ & 149691,9 & $\begin{array}{r}13544 \\
045,0\end{array}$ & 8156096,0 & 34,2 & 11,0 & 2711000,0 \\
\hline $\begin{array}{l}\text { Минимальное } \\
\text { значение }\end{array}$ & $-219991,4$ & $-244899,1$ & $-3449627,0$ & 1,8 & 0,0 & 3803,4 \\
\hline $\begin{array}{l}\text { Стандартное } \\
\text { отклонение }\end{array}$ & 47621,5 & 1173292,0 & 894159,8 & 3,0 & 1,2 & 577773,0 \\
\hline $\begin{array}{l}\text { Коэффициент } \\
\text { вариации }\end{array}$ & 12,2 & 1,6 & 11,5 & 0,5 & 1,1 & 1,3 \\
\hline
\end{tabular}

В таблице 2 содержится описательная статистика выборки по выбранным показателям стоимости, созданной интеллектуальным капиталом. Следует отметить значительную неоднородность выборки, что, однако, может быть объяснено разницей в размере ИК компаний. Также существенный разброс значений показателей экономической добавленной стоимости и рыночной добавленной стоимости, выраженный в значении коэффициента вариации, объясняется включением в выборку кризисных лет, во время которых произошло снижение финансовых результатов и значительное падение рыночной стоимости собственного капитала. Тем не менее включение их в выборку является оправданным, поскольку предполагается, что фирмы, характеризующиеся наличием интеллектуальных ресурсов, являются более устойчивыми к рыночным колебаниям.

В таблице 3 приведена описательная статистика прокси-показателей структурного капитала. Выборка неоднородна, среднеквадратичное отклонение каждого проксипоказателя превышает его среднее значение. Следует отметить значительное отклонение медианного значения от среднего, причем наиболее часто встречается нулевое количество патентов компании и отсутствие ERP-систем. 
Описательная статистика прокси-показателей структурного капитала

\begin{tabular}{|l|c|c|c|c|}
\hline & $\begin{array}{c}\text { Нематериальные } \\
\text { активы }\end{array}$ & Патенты & Наличие ERP & $\begin{array}{c}\text { Расходы } \\
\text { Ha R\&D }\end{array}$ \\
\hline Среднее значение & 219844,9 & 39,2 & 0,3 & 25139,2 \\
\hline Медиана & 79194,3 & 0,0 & 0,0 & 12114,8 \\
\hline Максимальное значение & 2684210,0 & 562,0 & 1,0 & 101000,0 \\
\hline Минимальное значение & 0,0 & 0,0 & 0,0 & 733,2 \\
\hline Стандартное отклонение & 405411,6 & 109,5 & 0,5 & 27520,8 \\
\hline Коэффициент вариации & 1,8 & 2,8 & 1,5 & 1,1 \\
\hline
\end{tabular}

Описательная статистика прокси-показателей человеческого капитала приведена в таблице 4. Выборка достаточно однородна по количеству сотрудников, что объясняется методологией ее составления, а также по доле собственников в числе совета директоров. Прочие прокси-показатели демонстрируют значительную неоднородность. Наиболее значительные колебания наблюдаются для показателя квалификации членов совета директоров.

Таблица 4

Описательная статистика прокси-показателей человеческого капитала

\begin{tabular}{|l|c|c|c|c|}
\hline & $\begin{array}{c}\text { Количество } \\
\text { сотрудников }\end{array}$ & $\begin{array}{c}\text { Затраты на } \\
\text { персонал }\end{array}$ & $\begin{array}{c}\text { Квалификация } \\
\text { совета директоров }\end{array}$ & $\begin{array}{c}\text { Доля } \\
\text { собственников в } \\
\text { числе директоров }\end{array}$ \\
\hline $\begin{array}{l}\text { Среднее } \\
\text { значение }\end{array}$ & 4985,0 & 182196,5 & 0,3 & 0,3 \\
\hline Медиана & 3379,0 & 109554,4 & 0,0 & 0,3 \\
\hline $\begin{array}{l}\text { Максимальное } \\
\text { Значение }\end{array}$ & 20231,0 & 1333000,0 & 2,0 & 0,9 \\
\hline $\begin{array}{l}\text { Минимальное } \\
\text { Значение }\end{array}$ & 166,0 & 2465,3 & 0,0 & 0,0 \\
\hline $\begin{array}{l}\text { Стандартное } \\
\text { отклонение }\end{array}$ & 4442,4 & 196419,1 & 0,5 & 0,3 \\
\hline $\begin{array}{l}\text { Коэффициент } \\
\text { вариации }\end{array}$ & 0,9 & 1,1 & 1,6 & 0,8 \\
\hline
\end{tabular}

В таблице 5 приведена описательная статистика прокси-показателей отношенческого капитала. Все представленные показатели не являются финансовыми. Три из них, а именно известность бренда и переменные, описывающие месторасположение офиса компании, определялись как бинарная, следовательно, среднее значение этих показателей, а также среднеквадратичное отклонение не способны описать структуру выборки. Медиана каждого из них говорит о том, что наиболее частым является нулевое значение. Прочие проксипоказатели распределены в выборке достаточно однородно.

Таблица 5

Описательная статистика прокси-показателей отношенческого капитала

\begin{tabular}{|l|c|c|c|c|c|c|}
\hline & $\begin{array}{l}\text { Известнос } \\
\text { ть бренда }\end{array}$ & $\begin{array}{c}\text { Һитируем } \\
\text { остьйта }\end{array}$ & $\begin{array}{c}\text { Нахождение } \\
\text { офиса в } \\
\text { столице }\end{array}$ & $\begin{array}{c}\text { Нахождение } \\
\text { офиса в городе-- } \\
\text { миллионнике }\end{array}$ & $\begin{array}{c}\text { Дочерние } \\
\text { компании }\end{array}$ & $\begin{array}{c}\text { Качество } \\
\text { сайта }\end{array}$ \\
\hline $\begin{array}{l}\text { Среднее } \\
\text { Значение }\end{array}$ & 0,2 & 4,1 & 0,5 & 0,2 & 26,6 & 2,7 \\
\hline Медиана & 0,0 & 4,0 & 0,0 & 0,0 & 25,0 & 3,0 \\
\hline Максимально & 1,0 & 7,0 & 1,0 & 1,0 & 176,0 & 4,0 \\
\hline
\end{tabular}




\begin{tabular}{|l|c|c|c|c|c|c|}
\hline е значение & & & & & & \\
\hline $\begin{array}{l}\text { Минимальное } \\
\text { значение }\end{array}$ & 0,0 & 0,0 & 0,0 & 0,0 & 0,0 & 0,0 \\
\hline $\begin{array}{l}\text { Стандартное } \\
\text { отклонение }\end{array}$ & 0,4 & 1,5 & 0,5 & 0,4 & 27,0 & 1,0 \\
\hline $\begin{array}{l}\text { Коэффициент } \\
\text { вариации }\end{array}$ & 2,2 & 0,4 & 1,1 & 2,4 & 1,0 & 0,4 \\
\hline
\end{tabular}

Для анализа наличия мультиколлинеарности в моделях была построена матрица корреляции между показателями. Единственными прокси-показателями ИК, между которыми была выявлена высокая статистически значимая корреляция, оказались количество сотрудников и величина расходов на них. В последующем исследовании эти переменные не использовались одновременно в рамках одной модели.

Таблица 6

Корреляционная матрица прокси-показателей ИК

\begin{tabular}{|l|l|l|l|l|l|l|}
\hline & $\begin{array}{l}\text { Известнос } \\
\text { ть бренда }\end{array}$ & $\begin{array}{c}\text { Цитируе } \\
\text { мость } \\
\text { сайта }\end{array}$ & $\begin{array}{c}\text { Нахождение } \\
\text { офиса в } \\
\text { столице }\end{array}$ & $\begin{array}{c}\text { Нахождение } \\
\text { офиса в городе-- } \\
\text { миллионнике }\end{array}$ & $\begin{array}{c}\text { Дочерние } \\
\text { компании }\end{array}$ & $\begin{array}{c}\text { Качество } \\
\text { сайта }\end{array}$ \\
\hline $\begin{array}{l}\text { Известность } \\
\text { бренда }\end{array}$ & 1,00 & 0,10 & 0,07 & $-0,06$ & 0,12 & $-0,19$ \\
\hline $\begin{array}{l}\text { Цитируемость } \\
\text { сайта }\end{array}$ & 0,10 & 1,00 & 0,06 & 0,23 & $-0,02$ & 0,36 \\
\hline $\begin{array}{l}\text { Нахождение } \\
\text { офиса в столице }\end{array}$ & 0,07 & 0,06 & 1,00 & 0,37 & 0,10 & 0,01 \\
\hline $\begin{array}{l}\text { Нахождение } \\
\text { офиса в городе- } \\
\text { миллионнике }\end{array}$ & $-0,06$ & 0,23 & 0,37 & 1,00 & 0,15 & 0,24 \\
\hline $\begin{array}{l}\text { Дочерние } \\
\text { компании }\end{array}$ & 0,12 & $-0,02$ & 0,10 & 0,15 & 1,00 & 0,15 \\
\hline Качество сайта & $-0,19$ & 0,36 & 0,01 & 0,24 & 0,15 & 1,00 \\
\hline
\end{tabular}

\section{5. Результаты тестирования гипотез}

Тестирование гипотез проводилось с помощью метода наименьших квадратов (OLS) на созданной выборке сбалансированных панельных данных с использованием эконометрического пакета Eviews.

Гипотеза о мультипликативном влиянии компонентов ИК на стоимость была проверена через проверку наличия линейной зависимости между показателями ИК и произведений пар прокси-показателей.

(1)

$$
Y=c_{0}+c_{i}\left(x_{i} \times x_{j}\right)+\varepsilon
$$

где:

$Y$ - показатель стоимости, созданной ИК;

$x$ - прокси-показатель ИК;

$n$ - количество прокси-показателей модели.

В результате тестирования, было выявлено, что для исследуемых компаний наблюдается статистически значимая нелинейная взаимосвязь между компонентами ИК и стоимостными показателями деятельности компании. Однако для каждого из показателей можно выделить свои особенности: 
Результаты тестирования гипотезы о мультипликативном эффекте воздействии компонентов ИК на добавленную стоимость

\begin{tabular}{|l|ll|}
\hline EVA & $\bullet$ & $18 \%$ моделей значимы \\
& $\bullet$ & В 74\% значимых наблюдается отрицательная связь \\
\hline FGV & $\bullet$ & $62 \%$ моделей значимы \\
& $\bullet$ & Наблюдается только сильная положительная связь \\
\hline VAIC & $\bullet$ & $55 \%$ моделей значимы \\
& $\bullet$ & В 98\% значимых наблюдается отрицательная связь \\
\hline MVA & $\bullet$ & $55 \%$ моделей значимы \\
& $\bullet$ & В 91\% значимых наблюдается отрицательная связь \\
\hline P/BV & $\bullet$ & $27 \%$ моделей значимы \\
& $\bullet$ & В 50\% значимых наблюдается положительная связь \\
\hline
\end{tabular}

Экономическая добавленная стоимость слабо отражает синергетические эффекты, создаваемые благодаря одновременному использованию разных компонентов ИК. Большинство моделей незначимы или имеют невысокую значимость $\left(\mathrm{R}^{2}=3-5 \%\right)$. Кроме того, около 70\% всех значимых моделей отразили негативный синергетический эффект, то есть сокращение EVA при увеличении компонентов ИК. Это может объясняться тем, что экономическая добавленная стоимость - краткосрочный показатель, при этом отдача от вложений в ИК происходит с задержкой, а расходы осуществляются в текущем периоде. Кроме того, эти инвестиции могут сопровождаться дополнительными издержками внедрения, что в краткосрочном периоде снижает финансовые результаты компании.

Наилучшие результаты отражения воздействия ИК на стоимость компании были выявлены у показателя стоимости будущего роста. Следовательно, можно предполагать значительный синергетический эффект от вложений в различные компоненты ИК, но при этом в текущем периоде эти вложения влекут за собой дополнительные расходы. С другой стороны, полученный результат следует из формулы расчета $\mathrm{FGV}$, согласно которой показатель сильно отрицательно зависит от величины капитализированной экономической добавленной стоимости, которая, как мы можем увидеть в таблице 7, отрицательно связана с совместным влиянием компонентов ИК.

Таким образом, регрессионный анализ показал, что хотя ИК способствует развитию компании и является источником конкурентных преимуществ, он может также разрушать добавленную стоимость, причем синергетический эффект от использования человеческого, структурного и отношенческого видов капитала для большинства компаний отрицательный.

Гипотеза 4 о влиянии структуры материальных и интеллектуальных активов была проверена с помощью модели вида:

$$
Y=c_{0}+c_{i}\left(x_{i} \div x_{j}\right)+\varepsilon
$$

где:

$Y$ - показатель стоимости, созданной ИК;

$x$ - прокси-показатель ИК;

$n$ - количество прокси-показателей модели.

Такая модель позволяет оценить влияние соотношения между компонентами ИК на процесс создания или разрушения добавленной стоимости компании.

Таблица 8

Результаты тестирования гипотезы о влиянии структуры ИК на добавленную стоимость

\begin{tabular}{|c|c|}
\hline EVA & • $\quad$ 21\% моделей значимы \\
\hline FGV & • $\quad 58 \%$ моделей значимы \\
\hline VAIC & • $\quad 63 \%$ моделей значимы \\
\hline
\end{tabular}




\begin{tabular}{|c|c|}
\hline MVA & • $\quad 32 \%$ моделей значимы \\
\hline $\mathrm{P} / \mathrm{BV}$ & • $\quad 16 \%$ моделей значимы \\
\hline
\end{tabular}

Как видно из таблицы 8, наиболее сильно влияние структуры интеллектуальных активов компании отражается в показателях интеллектуального коэффициента добавленной стоимости VAIC и стоимости будущего роста FGV. В то же время экономическая добавленная стоимость и коэффициент Q Тобина практически не имеют устойчивой связи со структурой портфеля активов.

Следует также отметить, что для моделей, где знаменателем являлся прокси человеческого капитала, характерна положительная зависимость соотношения компонентов ИК и показателя добавленной стоимости. Другими словами, если рассматривать человеческий капитал как основной ресурс компании, который благодаря использованию других активов, в том числе интеллектуальных, создает добавленную стоимость, то наблюдается довольно устойчивая связь между добавленной стоимостью и степенью развития ИК работников.

Очевидно, что для различных отраслей характерны различные сочетания интеллектуальных активов, поэтому при анализе выборки, состоящей из нескольких отраслей, связи могут быть менее устойчивы. Однако введение в модели дамми-переменных для обозначения отрасли лишь незначительно изменило результаты.

В целом результаты подтверждают, что структура интеллектуальных активов достаточно устойчиво линейно влияет на добавленную стоимость, созданную в результате деятельности компании. При этом влияние наблюдается и в краткосрочном, и в долгосрочном периоде. Следовательно, для создания стоимости компании необходимо учитывать не только накопленный объем ИК, но и соотношение между этими компонентами.

\section{6. Заключение}

Эффективность создания и использования знаний является ключевым фактором развития фирм и экономики в целом. Однако при этом знания достаточно сложны для анализа, поскольку они не имеют материального воплощения. В результате этого учет, исследование и управление знаниями являются актуальными областями развития финансового и управленческого учета, финансового менеджмента и смежных дисциплин.

В рамках данного исследования проверялся один из аспектов влияния ИК на деятельность компании, а именно то, каким образом компоненты ИК фирмы взаимодействуют между собой при создании стоимости фирмы. Однако даже на выборке компаний Великобритании, для которой характерна высокая эффективность в сфере создания, распространения и использования знаний, четкой однозначной связи выявлено не было. Использованные в моделях показатели добавленной стоимости отражают разнонаправленное влияние ИК на процесс создания стоимости компании.

Представленные результаты доказывают, что существует не только линейное влияние компонентов ИК на стоимость компании, но и создание синергетического эффекта. Однако при этом многие показатели добавленной стоимости отразили не только положительную, но и отрицательную синергию. Это может говорить о том, что компании вкладывают большие объемы средств в приобретение различных интеллектуальных активов, не учитывая при этом эффективность их работы. В результате этого неэффективность использования разных компонентов ИК накладывается друг на друга и создает отрицательный синергетический эффект. С другой стороны, возможно, что показатели добавленной стоимости, основанные на данных фондового рынка о стоимости компании, неверно отражают взаимовлияние компонентов ИК при создании стоимости фирмы вследствие неправильной оценки внешними инвесторами ИК компании, возникающей из-за слабого раскрытия информации о неосязаемых активах в отчетности компании.

Что касается структуры материальных и интеллектуальных активов, то линейная 
взаимосвязь со стоимостью фирмы достаточно нестабильна. Это может вызываться рядом причин: а) компании даже в рамках одной отрасли могут фокусироваться на разных компонентах ИК; б) существует оптимальная комбинация, отклонения от которой приводят к снижению эффективности в создании добавленной стоимости; в) учет активов, основанных на знаниях, очень несовершенен; г) не все компоненты ИК должны иметь соотношение; д) есть неучтенные факторы, которые оказывают существенное влияние на взаимосвязь структуры ИК и стоимости компании.

Дальнейшие исследования в области взаимовлияния компонентов ИК в процессе создания стоимости компании могут быть направлены на расширение выборки или увеличение ее однородности, добавление или изменение прокси-показателей компонентов ИК, а также на введение в модели факторов, оказывающих существенное влияние на процесс создания стоимости. Кроме того, может быть проверена зависимость нелинейного характера, например с использованием логарифмических моделей.

\section{Список литературы}

1. Байбурина Э.Р. Методы анализа интеллектуального капитала для современного устойчивого развития компании // Корпоративные финансы. 2007. № 3(3). С. 85-101.

2. Березинец И.В., Удовиченко О.М., Сысолятина Е.В. Оценка вклада интеллектуального капитала в создание ценности компании // Корпоративные финансы. 2010. № 3(15). С. 5-22.

3. Гаранина Т.А. Роль нематериальных активов в создании ценности компании: теоретические и практические аспекты // Корпоративные финансы. 2009. № 4 (12). С. 79-96.

4. Пунтилло П. (2009) Интеллектуальный капитал и эффективность деятельности компании. Результаты исследования по данным итальянских банков // Корпоративные финансы. 2009.№ 4(12). С. 96-115.

5. Руус Й., Пайк С., Фернстрем Л. ИК. Практика управления. СПб.: Высшая школа менеджмента, 2008.

6. Arthur, B. (1996), Increasing returns and the new world of business, Harvard Business Review, July-Aug., (1996) 1-10.

7. Bontis, N. (2001), Assessing knowledge assets: A review of the models used to measure intellectual capital, International Journal of Management Reviews, 3(1) (2000) 41-60.

8. Cañibano, L., García-Ayuso, M., and Sánchez, P. (2000), Accounting for Intangibles: A Literature Review, Journal of Accounting Literature, 19 (2000) 102-130.

9. Chen, M., Cheng, S., and Hwang, Y. (2005), An Empirical Investigation of the Relationship Between Intellectual Capital and Firms' Market Value and Financial Performance, Journal of Intellectual Capital, 6(2) (2005) 159-176.

10. Daum, J.H. (2001), Value Drivers Intangible Assets - Do We Need A New Approach to Financial and Management Accounting. A Blueprint for an Improved Management System. P. 22.

11. Di'ez, J. M., Ochoa, M. L., Prieto, M.B., Santidria'n, A. (2010), Intellectual capital and value creation in Spanish firms, Journal of Intellectual Capital, 11(3) (2010) 348-367.

12. Huang, C., Wang, M.-C. (2008) The Effects of Economic Value Added and Intellectual Capital on the Market Value of Firms: An Empirical Study, International Journal of Management, 25(4) (2008) 722-731.

13. Huang, C., Liu, J. (2005), Exploration for the Relationship Between Innovation, IT and Performance, Journal of Intellectual Capital, 6(2) (2005) 237-252.

14. Kimura, H., Cruz Basso, L.F., Nogueira, S.G., de Barros, L.J. (2010), The impact of intellectual capital on value added of Brazilian companies traded at the BMF-Bovespa, Journal of International Finance \& Economics, 10(2) (2010) 1-11.

15. Lev, B. (1999), R\&D and Capital Markets, Journal of Applied Corporate Finance, (1999) 
21-35.

16. Lev, B., Zarowin, P. (1999) The Boundaries of Financial Reporting and How to Extand Them, Journal of Accounting Research, 37(2) (1999) 353-385.

17. Molodchik, M.A., Shakina, E.A., Bykova, A. (2012), Intellectual Capital Transformation Evaluating Model, Journal of Intellectual Capital, 4(13) 2012 1-13.

18. Mouritsen, J., Bukh, N.D. (2000), A guideline for intellectual capital statements - a key to knowledge management, Danish Agency for Trade and Industry.

19. Pulić, A. The Physical and Intellectual Capital of Austrian Banks. URL: http://www.vaicon.net/start.htm (21.02.2011).

20. Pulić, A. (2000) VAIC ${ }^{\mathrm{TM}}$ - an accounting tool for IC management, International Journal of Technology Management, 20(5-8) (2000) 702-714.

21. Riahi-Belkaoui, A. (2003), Intellectual capital and firm performance of US multinational firms, Journal of Intellectual capital, 4(2) (2003).

22. Rodov, I., Leliaert, P. (2003), FiMIAM: financial method of intangible assets measurement, Journal of Intellectual Capital, 3(3) (2003) 323-336.

23. Shakina, E.A., Barajas, Alonso A. (2012), The Relationship between Intellectual Capital Quality and Corporate Performance: An Empirical Study of Russian and European Companies, Economic Annals, 57(192) 2012 79-98.

24. Shiu, H.-J. (2006), The Application of the Value Added Intellectual Coefficient to Measure Corporate Performance: Evidence from Technological Firms, International Journal of Management, 23(2) (2006) 356-365.

25. Starowiz, D., Marr, B. (2005), Understanding corporate value: managing and reporting intellectual capital. Chartered Institute of Management Accountants, Cranfield University.

26. Stern, J.M., Shiely, J.S., Ross, I. (2003), The EVA Challenge: Implementing Value-Added Change in an Organization, Wiley finance: John Wiley and Sons.

27. Stewart, T.A. (2002), The case against knowledge management, Business 2.0, 3(2) (2002).

28. Tobin, J. (1969), A general equilibrium approach to monetary theory, Journal of Money Credit and Banking, 1(1) (1969) 15-29.

29. Youndt, M., Subramaniam, M., Snell, S. (2004), Intellectual capital profiles: An examination of investments and returns, Journal of Management Studies, 41 (2) (2004) 335-362.

30. Zeghal, D. (2000), New assets for the new economy, FMI Journal, 11(2) (2000).

31. Zickgraf, S., Mertins, K., Will, M., Wang, W.-H., Meyer, C. (2007), InCaS: Intellectual Capital Statement, European ICS Guideline. 